\title{
Türkçe Metinlerde Duygu Analizi Için Farklı Makine Öğrenmesi Yöntemlerinin Karşılaştırılması
}

\section{Comparison of Different Machine Learning Approaches for Emotion Analysis in Turkish}

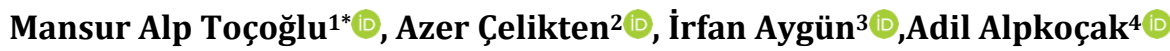 \\ 1,2,3 Manisa Celal Bayar Üniversitesi, Hasan Ferdi Turgutlu Teknoloji Fakültesi, Yazılım Mühendisliği Bölümü, \\ Turgutlu, Manisa, TÜRKIYE \\ ${ }^{4}$ Dokuz Eylül Üniversitesi Mühendislik Fakültesi, Bilgisayar Mühendisliği Bölümü, Buca, İzmir, TÜRKIYE \\ Sorumlu Yazar / Corresponding Author*: alpkocak@ceng.deu.edu.tr
}

Atıf sekli/How to cite: TOÇOĞLU, M., A., ÇELIKTEN, A., AYGÜN, I., ALPKOÇAK, A. (2019). Türkçe Metinlerde Duygu Analizi için Farklı Makine Öğrenmesi Yöntemlerinin Karşılaştırılması. DEUFMD, 21(63), 719-725.

$\ddot{0} \mathbf{z}$

Bu çalışmada, Türkçe metinlerden duygu çıkarımı alanında kullanılan TREMO veri seti üzerinde farklı makine öğrenmesi algoritmalarının sınıflandırma sonuçları karşılaştırılmıştır. Duygu analizi bir metin sınıflandırma problemi olarak ele alınmış ve Yapay Sinir Ağları (YSA), Destek Vektör Makineleri (DVM), Random Forest (RF) ve K-En Yakın Komşu (KEYK) algortimaları olmak üzere dört yaklașım incelenmiștir. İncelenen duygu kategorileri olarak veri setinin sağladığı, mutluluk, korku, öfke, üzüntü, tiksinme ve şaşırma kategorileri kullanılmıştır. Veri ön işleme bölümünde, veri setini oluşturan kelimelerin kökleri ilk beş karakter (F5) yöntemi kullanılarak tespit edilmiştir. Kelimeler kök haline getirildikten sonra Vektör Uzay Modeli ile veri seti modellenmiş ve her duygu için en önemli ilk 500 kelime Karşılıklı Bilgi (Mutual Information-MI) yöntemi ile tespit edilmiștir. Sınıflandırma sonuçlarının karşılaştırılmasında doğruluk metriği esas alınmıştır. Deneysel çalışma sonuçlarına göre, YSA algoritması en iyi sonucu vermiştir. DVM, RF ve KEYK algoritmaları ise bu sıra ile azalan başarım göstermişlerdir.

Anahtar Kelimeler: TREMO, Duygu Analizi, Makine Öğrenmesi, Metin Madenciliği

\section{Abstract}

In this research, the classification results of different Machine Learning Algorithms were compared on the validated TREMO data set used in the field of emotion extraction from Turkish texts. Emotion analysis was considered as text classification problem and four different machine algorithms, Artificial Neural Networks (ANN), Support Vector Machines (SVM), Random Forest (RF) and K-Nearest Neighbor (KNN) have been investigated. The categories provided by the data set, which are happiness, fear, anger, sadness, disgust and surprise, were used as emotion categories. In the preprocessing phase, stemming process was performed using the truncate at five (F5) method. After stemming process, the data set was modeled using the Vector Space Model. After that, the first 500 words for each emotion in the data set were identified by the Mutual Information (MI) formula. The comparison of classification results was based on accuracy metric. According to experimental study results, the ANN classifier was performed best, and SVM, RF and KNN performed, in descending order. Keywords: TREMO, Emotion Analysis, Machine Learning, Text Mining 


\section{Giriş}

Sosyal medya uygulamalarının kullanımındaki artış, beraberinde oldukça büyük miktarda işlenmemiş metin verilerine ulaşma imkanı sağlamıştır. Bu imkan doğrultusunda, bahsedilen büyük miktardaki ham veriden anlamlı verilerin çıkarılması gündeme gelmektedir. Fakat bu tür yapılandırılmamıș verilerden anlamlı bilgilerin çıkarılması çok karmașık ve pahalı süreçlerin uygulanmasını gerektirmektedir. Literatürde bu sorunun üstesinden gelmek için birçok sınıflandırma algoritması geliștirilmiştir. $\mathrm{Bu}$ algoritmaların temel amacl, farklı kategoriler oluşturmak için metin verilerini benzer yapılara ve anlamlara göre sinıflandırmaktır. Yeni oluşturulan bu kategori grupları sayesinde yapisal olmayan metin dosyalarını sınıflandırmak mümkün hale gelecektir.

Twitter ve Facebook gibi sosyal medya araçları, herhangi bir metinden bilgi çıkarma sürecinde büyük veri kaynakları olarak önemli role sahiptir. Bunun en önemli nedeni, bu uygulamalar sayesinde üretilen metin verilerinin her geçen gün önemli oranda artmasıdır. Fakat bu kaynaklar kategorize edilmediği için sınıflandırma algoritmalarının gereksinimlerini karşılamamaktadır. Literatürde bu sorunu çözmek için oluşturulan birçok veri seti bulunmaktadır. Örneklerden birisi, Türkçe metin sınıflandırması için olușturulan TTC-3600 Benchmark veri setidir [1].

Literatürde İngilizce için duygu sınıflandırması yapmak amacıyla oluşturulan birçok veri seti bulunmaktadır. En sık kullanılanlardan birisi de İngiliz merkezli Uluslararası Duygu Öncüler ve Tepkiler Anketi (ISEAR) veri setidir [2]. 37 farklı ülkeden üç bin gönüllü, bu projeye mutluluk, korku, öfke, üzüntü, iğrenme, utanç ve suçluluk duyguları ile ilgili yașam deneyimlerini ve tepkilerini yazarak katılmışlardır. Bu veri seti duygu sınıflandırması için yapılan bazı çalıșmalarda kullanılmaktadır [3]. Giachanou ve Crestani yaptıkları çalışmada Twitter'da belirli bir konuyla ilgili yapılan paylaşımlarından fikir çıkarımı konusunu ele almıştır [4]. Bu hedefe ulaşmak için kullandıkları veri setlerinden biri 50 başlık ve 5.000 tweetten oluşmaktadır [5]. İkinci veri seti ise fikirlerle ilgili terimlerin tanımlanmasında kullanılacak 2.000'den fazla kelimeden oluşan AFINN sözlüğüdür [6]. Go, Bhayani ve Huang, tweet'leri negatif ya da pozitif olarak sınıflandırmayı amaçlamışlardır. Olumlu ve olumsuz duygular arasındaki farkları gösteren ifadelere göre toplanan tweetler ile veri setleri oluşturulmuștur. Mohammad [7], kelimeduygu birliği sözlüklerinin, n-gram özelliklerini kullanmaktan daha iyi sonuçlar verip vermeyeceğini belirlemeye odaklanmıştır. Sonuç olarak, duygu sözlügü özelliklerinin yeni alanlarda n-gram özelliklerini kullanmaktan daha iyi sonuçlar verdiğini gözlemlemiştir. Strapparava ve Valitutti [9], bu adımları başarmak için Ekman [8] tarafından belirlenen altı duygu için oluşturulan WordNet Affect sözlüğünü kullanmıștır. Eğitim veri seti için SemEval-2007 Affective Text Corpus'u kullanılmıștır [10]. Chaffer ve Inkpen [11] tarafından yapılan çalıșmada; haber başlıkları, peri masalları ve bloglar gibi kaynaklardan heterojen bir veri seti kullanılarak altı farklı duygu çıkarılmıştır. Kouloumpis, Wilson ve Moore [12], denetimli öğrenme yaklașımları ile öznitelikleri kullanmanın Twitter duyarlılık analizi üzerindeki etkilerini değerlendirmiștir. $\mathrm{Bu}$ hedefe ulaşmak için üç farklı Twitter mesaj yapısı kullanılmıştır. Bunlardan ikisi olan etiketlenmiș kelimeler ve ifadelerden olușan veri setleri, eğitim veri setleri olarak kullanılmıştır. Modelleri test edebilmek için ise açıklamalı bir veri setinden faydalanılmıştır. Yang, Lin ve Chen [13] çalışmalarında dört duygu kategorisi; neșe, mutluluk, üzüntü ve korku için duygu sinıflandırma problemleri üzerine odaklanmıștır. Blog yazılarını ve ifadelerini eğitim veri setleri șeklinde kullanarak Destek Vektör Makineleri ile koșullu rastgele alan sınıflandırıcılarının elde ettiği sonuçlar karşılaştırılmıştır.

Türkçe metinlerden duygu çıkarımı yapabilmek için, bu alanda sınıflandırılmış bir veri setine ihtiyaç duyulmaktadır. Bu çalışmada Türkçe duygu analizi için hazırlanmış olan TREMO veri seti kullanılmıştır [14]. Çalışmada faydalanılan veri setinin duygu analizi konusunda Türkçe dili için farklı bir alternatifi bulunmamaktadır. Bu çalışmada 25.989 belge ile veri setinin doğrulanmış hali kullanılmıştır. TREMO veri setine yönelik analizlerin yapıldığı çalıșmada en yüksek sınıflandırma sonuçlarının Destek Vektör Makineleri (DVM, Ing., Support Vector Machines) ile elde edildiği saptanmıștır. Bu çalıșmada ise Yapay Sinir Ağları (YSA, Ing., Artificial Neural Network ), DVM, Random Forest (RF) ve k-En Yakın Komșu (KEYK, Ing., k-Nearest Neighbor) karșılaștırılmıștır. Sonuçlar incelendiğinde YSA kullanılarak geliştirilmiş sinıflandırma modelinin daha yüksek sonuçlar verdiği gözlemlenmiștir. 
Calıșmanın kalanı ise aşağıdaki șekilde düzenlenmiștir. 2. Bölümde makalenin içeriğinde kullanılmış olan materyaller ve metotlara yer verilmiștir. 3. Bölümde çalıșmada gerçekleștirilen deneylerin sonuçları paylaşılıp değerlendirilmiştir. Son bölümde elde edilen sonuçların kısa bir özeti paylaşılıp makalenin literatüre katkıları paylaşılmıştır.

\section{Materyal ve Yöntem}

Bu bölümde çalıșmanın içeriğinde kullanılan veri seti ve yöntemler hakkında bilgi verilmiștir.

\subsection{TREMO Veri Seti}

Veri setinin hazırlanması için farklı yaș gruplarından ve farklı bölgelerde yaşayan 5.000 katılımcı ile bir anket çalışması yapılmıştır. Bu ankette katılımcılardan Ekman'ın tarif ettiği altı duygu kategorisi için anılarını ve yaşadıkları deneyimlerini metin olarak paylașmaları istenmiștir. Anket sonucunda, 4.709 adet katılımcının dokümanları onaylanmış ve 27.350 adet belge toplanmıștır. Belgelerin duygu kategorilerine göre dağılım sayısı Tablo 1'de yer almaktadır.

Tablo 1. Belgelerin duygu kategorilerine göre dağılımı.

\begin{tabular}{cccccc}
\hline Mutluluk & Korku & Öfke & Üzüntü & Tiksinme & Şaşırma \\
\hline 4.700 & 4.616 & 4.636 & 4.664 & 4.522 & 4.212 \\
\hline
\end{tabular}

TREMO veri seti sınıflandırma algoritmalarından eğitim modeli oluşturulurken belirsiz ve sahte belgelerin olumsuz etkilerinin azaltılması amacıyla doğrulama sürecinden geçirilmiştir. Doğrulama işlemi için her belge en az üç, en fazla 5 farklı kullanıcıya sunularak oy birliği veya oy çokluğuyla belgenin duygu kategorisine karar verilmiștir. Doğrulama ișleminde 48 gönüllü kullanıcı tüm belgeler için 92.986 oy vermiştir. Duygu kategorileri belirsiz olan ve veri setinin \%4,98'ini oluşturan 1.361 belge oylama sonucunda sistemden çıkarılarak doğrulanmış veri seti elde edilmiștir. Tablo 2'de belgelerin duygu kategorilerine göre dağılımları yer almaktadır.
Tablo 2. Doğrulama işleminden sonra belgelerin duygu sınıflarına göre dağılımı

\begin{tabular}{lrr}
\hline $\begin{array}{l}\text { Duygu } \\
\text { sınıfi }\end{array}$ & $\begin{array}{r}\text { Orijinal } \\
\text { belge sayısı }\end{array}$ & $\begin{array}{r}\text { Doğrulama } \\
\text { işleminden } \\
\text { sonraki belge } \\
\text { sayısı }\end{array}$ \\
\hline Mutluluk & 4.700 & 5.229 \\
Korku & 4.616 & 4.393 \\
Öfke & 4.636 & 4.723 \\
Üzüntü & 4.664 & 5.021 \\
Tiksinme & 4.522 & 3.620 \\
Şaşırma & 4.212 & 3.003 \\
\hline Toplam & $\mathbf{2 7 . 3 5 0}$ & $\mathbf{2 5 . 9 8 9}$ \\
\hline
\end{tabular}

\subsection{Yöntem}

$\mathrm{Bu}$ bölümde doğrulanmış veri seti üzerinde duygu analizi yapmak için kullanılan yöntemin adımları açıklanmıştır. Sınıflandırma işlemine geçmeden önce veri ön işleme ve öznitelik seçimi gerçekleştirilmiştir. Veri ön işleme adımında gereksiz terimler ve sayısal değerler silindikten sonra belge metinlerindeki kelimelerin kök bulma işlemi yapılmıştır. Kök bulma işlemi için sabit önek (fixed prefix stemming) yöntemi, öznitelik seçimi için ise mutual information (MI) yöntemi kullanılmıştır [15]. Veri ön işleme ve öznitelik seçimi aşamalarından sonra veri seti TFxIDF ağırlıklandırma yöntemi kullanılarak vektör uzay modeli olușturulmuștur. Son olarak YSA kullanılarak sınıflandırma işlemi gerçekleştirilmiş ve sonuçlar açıklanmıştır.

\subsubsection{Veri Ön İşleme}

Veri setini sınıflandırma işlemine hazırlamak için veri ön işlemeye ihtiyaç vardır. İlk olarak metin içerisindeki kelimelerin köklerini bulmak amacıyla sabit önek yöntemi kullanılmıștır. Bu yöntemde kelimenin ilk n karakteri kök olarak alınarak geri kalan kısımları kesilir. $\mathrm{Bu}$ çalışmada n değeri 5 olarak kabul edilmiștir (F5). Bunun nedeni, F5 yönteminin F4 ve F7 yöntemlerine göre optimum performans gösterdiğinin tespit edilmesidir [16]. Böylece, veri setinde kök bulma işlemi için F5 metodu uygulanmıştır. Daha sonra noktalama işaretleri, sayısal değerler, fazla boşluklar ve gereksiz terimler silinerek veri ön işleme adımı tamamlanmıştır. Tablo 3'te Ön işlemeden geçirilmiş veri setinin sayısal değerleri paylaşılmıștır. 
Tablo 3. Ön ișlemeden geçirilmiş veri setinin sayısal değerleri

\begin{tabular}{lccc}
\hline $\begin{array}{l}\text { TREMO } \\
\text { Versiyonu }\end{array}$ & $\begin{array}{c}\text { Toplam } \\
\text { Belge }\end{array}$ & $\begin{array}{l}\text { Toplam } \\
\text { Kelime }\end{array}$ & $\begin{array}{l}\text { Biricik } \\
\text { Kelime }\end{array}$ \\
\hline F5_V & 25.989 & 126.593 & 6.280 \\
\hline
\end{tabular}

\subsection{2 Öznitelik Seçimi}

Veri setindeki önemsiz değerleri eleyerek önemli öznitelikleri tespit etmek ve sınıflandırma ișlemi sırasında performans artıșı sağlamak amacıyla öznitelik seçimi yapılmıștır. Duygu kategorileri için en önemli öznitelikleri belirlemek için karşıllıklı bilgi yöntemi kullanılmıştır. Her duygu sınıfı için öznitelikler önem derecesine göre tekrar sıralanarak, duygu sınıfları için en önemli öznitelikler seçilmiștir. Önem değerine göre her duygu sınıfı için ilk 500 öznitelik seçilmiştir.

Veri ön işleme ve öznitelik seçim aşamaları tamamlandıktan sonra, veri seti vektör uzay modeline dönüştürülmüștür. $\mathrm{Bu}$ modelde her belge Document Term Matrisi (DTM)'de bir vektör olarak temsil edilir ve her satır terimlerini sütunların oluşturduğu bir vektörden olușur. DTM'de sadece belgelere karşılık gelen hücrelerde veri bulunmaktadır, diğer hücrelerin değeri 0'dır. Vektör uzay modelinde TFxIDF ağırlıklandırma yöntemi kullanılmıştır [15].

\section{Bulgular}

$\mathrm{Bu}$ bölümde, iki farklı makine öğrenme algoritmasının TREMO veri seti üzerinde uygulanmasıyla elde edilen sonuçlar karşılaştırılmıștır. Buradaki hedef, [14] çalışmasında en yüksek doğruluk değerini veren DVM algoritmasından daha yüksek doğruluk değerini elde edilebilecek bir algoritma tespit etmektir. Bu amaç doğrultusunda, çok iyi bilinen bir makine öğrenme algoritması olan YSA kullanılmıștır.

Çalışmada kullanılan YSA, 5 katmandan oluşan Multi Layer Perceptron(MLP) ağ mimarisi modeli kullanılarak olușturulmuștur. $\mathrm{Bu}$ katmanlar sırasıyla 1.397 adet nöron bulunduran giriș katmanı, her bir katmanda 450 adet nöron bulunduran 3 adet ara katman ve 6 adet nöron bulunduran çıtı katmanıdır. 3 adet ara katman kullanılmasının nedeni 3 katmanlı bir yapının test edilen diğer katman sayılarına sahip sinir ağlarına oranla daha iyi performansa sahip olmasıdır. Şekil 1'de katman sayılarına göre doğruluk değerleri yer almaktadır. YSA modelinin katmanlarında bulunan nöron sayıları belirli kurallara göre belirlenmiştir. Giriş katmanında bulunan 1.397 adet nöron TREMO veri seti üzerinde ilk 500 öznitelik seçimi yöntemi ile elde edilmiş benzersiz kelimeleri temsil etmektedir. Ara katmanlarda 450 adet nöron kullanılması ile daha yüksek doğruluk değeri elde edilmiştir. Şekil 2'de modelin farklı nöron sayıları ile test edilmesi sonucu elde edilen doğruluk değerleri gösterilmektedir. Çıkış katmanında bulunan 6 adet nöron sınıflandırmada kullanılan duygu kategorilerini ifade etmektedir. Bunlar sirasiyla; mutluluk, korku, öfke, üzüntü, tiksinme ve șașırma duygularıdır. YSA modelinde gizli katmanlarda rectifier aktivasyon fonksiyonunu, çıktı katmanında ise softmax aktivasyon fonksiyonu kullanılmıştır. Ayrıca, sinir ağındaki en optimal ağırlıkları bulmada kullanılan optimizasyon algoritması Olasılıksal Dereceli Azalma (Stochastic Gradient Descent) algoritmasıdır. Bununla beraber modelde çıktı katmanı 6 adet nörondan oluştuğu için logaritmik kayıp fonksiyonu olarak kategorik çapraz entropi kullanılmıștır.

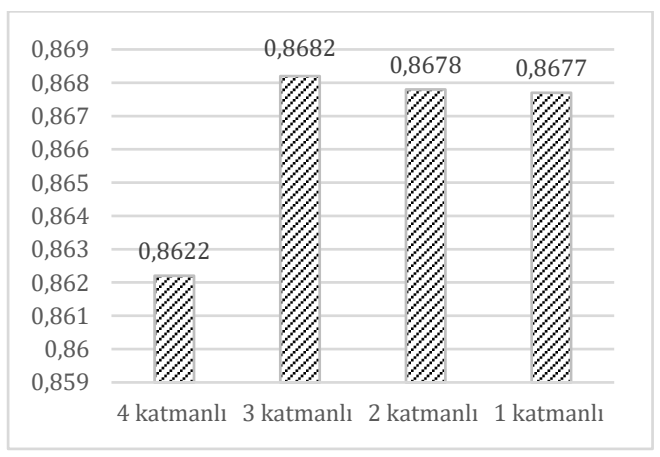

Şekil 1. Ara katman farklılıklarına göre YSA modelinin verdiği genel doğruluk değerleri. 
DEU FMD 21(63), 719-725, 2019

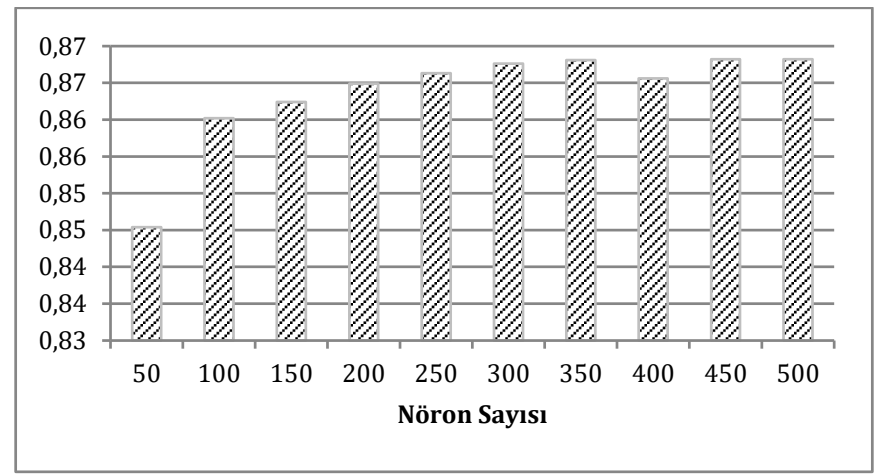

Şekil 2. Ara katmanı olușturan nöron sayılarının farklılıklarına göre YSA modelinin verdiği genel doğruluk değerleri

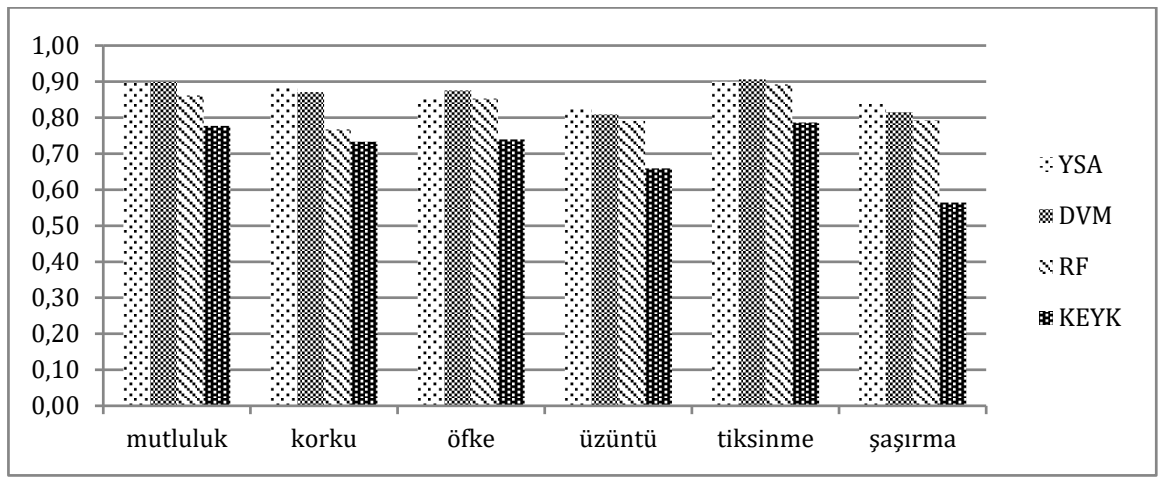

Şekil 3 YSA, DVM, RF ve KEYK algoritmalarının duygu kategorileri bazında doğruluk değerlerinin karşılaştırılması

$\mathrm{Bu}$ çalışmada, YSA, DVM, RF ve KEYK algoritmalarının ürettiği sınıflandırma sonuçları 10 Katmanlı Çarpraz Doğrulama yöntemi kullanılarak değerlendirilmiştir. Şekil 4'de her iki algoritmalarının genel doğruluk değerleri karşılaştırılmıştır. Sonuçlar incelendiğinde, YSA algoritmasının 0,0045 gibi az bir farkla da olsa DVM algoritmasına üstünlüğü gözükmektedir.

Genel doğruluk değerlerinin dișında bir diğer incelenmesi gereken sonuçlar ise her bir duygu kategorisi için hesaplanan doğruluk değerleridir. Böylece, herbir duygunun bireysel sınıflandırma performansı sergilenebilmektedir. Şekil 3'de YSA, DVM, RF ve KEYK algoritmalarının duygu kategorileri bazında doğruluk değerlerinin karşılaștırılması gösterilmiștir. Öncelikle, her iki algoritma için de üzüntü kategorisi en düşük, tiksinme kategorisi en yüksek doğruluk değerlerini vermiştir. Bunun yanında, YSA algoritması korku, üzüntü ve şaşırma duygularında DVM algoritmasına üstünlük kurarken, mutluluk, öfke ve tiksinme kategorilerinde DVM algoritmasının YSA algoritmasına üstünlüğü mevcuttur.

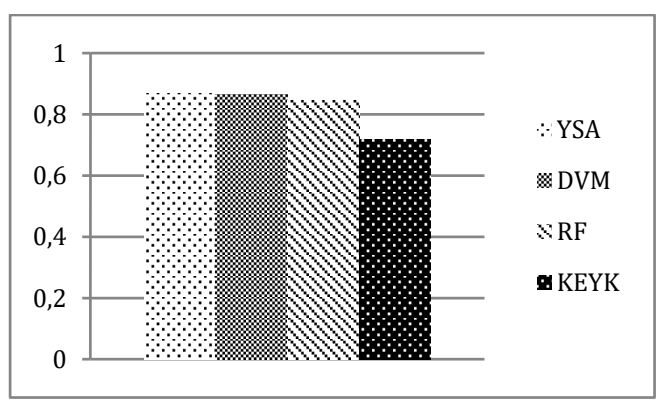

Şekil 4. YSA, DVM, RF ve KEYK algoritmalarının genel doğruluk değerlerinin karşılaştırılması

Tablo 5, 6, 7 ve 8'de sirasiyla YSA, DVM, RF ve KEYK algoritmaları için elde edilen karışıklık matrisleri gösterilmektedir. $\mathrm{Bu}$ matrislerin 
DEU FMD 21(63), 719-725, 2019

paylaşılmasındaki temel amaç, hangi duygunun hangi duyguyla daha çok ya da daha az karıştığını tespit etmektir. Her iki algoritmanın sonuçlarına bakıldığında, aynı duygu kategorilerinin birbirleriyle en çok ve en az miktarlarda karışıklık gösterdikleri tespit edilebilmektedir. Örneğin Tablo 5'de şaşırma duygusunun 247 belge sayısıyla en çok mutluluk duygusuyla, 16 belge sayısıyla da en az tiksinme duygusuyla karıștığı gözlemlenebilmektedir.

Tablo 5. YSA algoritmasının kullanımı sonucu elde edilen karışıklık matrisi

\begin{tabular}{lccccccc}
\hline & Mutluluk & Korku & Öfke & Üzüntü & Tiksinme & Şaşırma & Doğruluk \\
\hline Mutluluk & 4.682 & 89 & 189 & 160 & 0 & 100 & 0,8969 \\
Korku & 106 & 3.901 & 104 & 209 & 68 & 32 & 0,8826 \\
Öfke & 157 & 112 & 3.798 & 216 & 91 & 66 & 0,8554 \\
Üzüntü & 369 & 118 & 219 & 3.980 & 9 & 105 & 0,8292 \\
Tiksinme & 22 & 82 & 214 & 20 & 3.509 & 53 & 0,8997 \\
Şaşırma & 247 & 55 & 112 & 85 & 16 & 2.695 & 0,8396 \\
\hline
\end{tabular}

Tablo 6. DVM algoritmasının kullanımı sonucu elde edilen karışıklık matrisi

\begin{tabular}{lccccccc}
\hline & Mutluluk & Korku & Öfke & Üzüntü & Tiksinme & Şaşırma & Doğruluk \\
\hline Mutluluk & 4.701 & 95 & 128 & 146 & 15 & 144 & 0,8990 \\
Korku & 171 & 3.826 & 100 & 210 & 59 & 27 & 0,8709 \\
Öfke & 210 & 81 & 4.134 & 200 & 52 & 46 & 0,8753 \\
Üzüntü & 480 & 129 & 234 & 4.060 & 24 & 94 & 0,8086 \\
Tiksinme & 91 & 65 & 143 & 28 & 3.279 & 14 & 0,9058 \\
Şaşırma & 296 & 48 & 106 & 91 & 14 & 2.448 & 0,8152 \\
\hline
\end{tabular}

Tablo 7. Random Forest (RF) algoritmasının kullanımı sonucu elde edilen karıșıklık matrisi

\begin{tabular}{lccccccc}
\hline & Mutluluk & Korku & Öfke & Üzüntü & Tiksinme & Şaşırma & Doğruluk \\
\hline Mutluluk & 4.504 & 89 & 152 & 306 & 38 & 140 & 0,8614 \\
Korku & 725 & 3.830 & 134 & 215 & 64 & 25 & 0,7671 \\
Öfke & 217 & 81 & 4.029 & 230 & 118 & 48 & 0,8531 \\
Üzüntü & 439 & 176 & 295 & 3.971 & 45 & 95 & 0,7909 \\
Tiksinme & 69 & 82 & 164 & 52 & 3.229 & 24 & 0,8920 \\
Şaşırma & 282 & 61 & 103 & 150 & 26 & 2.381 & 0,7929 \\
\hline
\end{tabular}

Tablo 8. KNN algoritmasının kullanımı sonucu elde edilen karışıklık matrisi

\begin{tabular}{lccccccc}
\hline & Mutluluk & Korku & Öfke & Üzüntü & Tiksinme & Şaşırma & Doğruluk \\
\hline Mutluluk & 4.064 & 179 & 245 & 368 & 65 & 308 & 0,7772 \\
Korku & 274 & 3.367 & 211 & 333 & 97 & 311 & 0,7331 \\
Öfke & 363 & 138 & 3.419 & 325 & 207 & 171 & 0,7396 \\
Üzüntü & 625 & 380 & 387 & 3.309 & 84 & 236 & 0,6590 \\
Tiksinme & 155 & 174 & 274 & 94 & 2.846 & 77 & 0,7862 \\
Şaşırma & 561 & 161 & 255 & 248 & 83 & 1.695 & 0,5644 \\
\hline
\end{tabular}




\section{Tartışma ve Sonuç}

$\mathrm{Bu}$ çalıșmada, doğrulanmıș TREMO veri seti üzerinde literatürde yaygınlıkla kullanılan YSA, DVM, RF ve KEYK makine ögrrenme algoritmaları doğruluk metriği kullanılarak duygu analizi sonuçları karşılaştırılmıştır. Bunun için öncelikle TREMO veri seti ön ișleme bölümünden geçirilmiştir ve F5 yöntemi ile TREMO'da bulunan bütün kelimelerin kökleri bulunmuştur. Sonrasında, veri setindeki her bir duygu için en önemli ilk 500 kelime MI formülü kullanılarak tespit edilerek özellik seçimi yapılmıștır ve veri seti uzay vektör modeli kullanılarak modellenmiştir. Elde edilen bu veri modeli YSA, DVM, RF ve KEYK algoritmalarını eğitmek ve test etmek amacıyla kullanılmıștır. Değerlendirme metriği olarak doğruluk değerinin kullanıldığı sınıflandırma sonuçlarına bakıldığında, genel doğruluk değerlerinde YSA algoritmasının diğer üç algoritmalara göre üstünlük kurduğu gözlemlenmiștir. Sonuçlar duygu kategorileri incelendiğinde YSA ve DVM algoritmaları birbiriyle yakın yakın sonuçlar üretmişlerdir.

Gelecekte yapılması planlanan ișler arasında, TREMO veri setinin YSA ağlarının temelini oluşturduğu derin öğrenme yöntemleri kullanılarak duygu analizi yapılması vardır.

\section{Kaynakça}

[1] Kılınç, D., Özçift, A., Bozyigit, F., Yıldırım, P., Yücalar, F., \& Borandag, E. 2017. TTC-3600: A New Benchmark Dataset for Turkish Text Categorization. Journal of Information Science, Cilt. 43, s. 174-185 DOI: https://doi.org/10.1177/0165551515620551

[2] Scherer, K.R., Wallbott, H.G. 1994. Evidence for Universality and Cultural Variation of Differential Emotion Response Patterning. Journal of Personality and Social Psychology, Cilt. 67, s. 55. DOI: http://dx.doi.org/10.1037/0022-3514.67.1.55

[3] Danisman, T., Alpkocak, A. 2008. Feeler: Emotion Classification of Text Using Vector Space Model. AISB 2008 Convention Communication, Interaction and Social Intelligence, 1-4 Nisan, Aberden, 53-59.

[4] Giachanou, A., Crestani, F. 2016. Opinion Retrieval in Twitter Using Stylistic Variations. 31. Annual ACM Symposium on Applied Computing, 4-8 Nisan, Pisa, 1077-1079.

[5] Luo, Z., Osborne, M., Wang, T. 2015. An Effective Approach to Tweets Opinion Retrieval. World Wide Web, Cilt. 18, s. 545-566.

[6] Go, A., Bhayani, R., Huang, L. 2009. Twitter Sentiment Classification Using Distant Supervision. CS224N Project Report, Stanford, 1(12).

[7] Mohammad, S. 2012. Portable Features for Classifying Emotional Text. North American Chapter of the Association for Computational Linguistics: Human Language Technologies, 3-8 Haziran, Montreal, 587-591.
[8] Ekman, P. 1992. An Argument for Basic Emotions, Cognition \& Emotion. Cilt. 6, s. 169-200..

[9] Strapparava, C., Valitutti, A. 2004. Wordnet Affect: an Affective Extension of Wordnet. International Conference on Language Resources and Evaluation, 26-28 Mayıs, Lizbon, 1083-1086.

[10] Strapparava, C., Mihalcea, R. 2007. Semeval-2007 task 14: Affective Text. 4. International Workshop on Semantic Evaluations, 23-24 Haziran, Prag, 70-74.

[11] Chaffar, S., Inkpen, D. 2011. Using a Heterogeneous Dataset for Emotion Analysis in Text. Conference on Artificial Intelligence, 25-27 Mayıs, St. John's, 62-67.

[12] Kouloumpis, E., Wilson, T., Moore, J.D. 2011. Twitter Sentiment Analysis: The Good the Bad and the Omg!. 5. International Conference on Weblogs and Social Media, 17-21 Temmuz, Barselona, 538-541.

[13] Yang, C., Lin, K. H.Y., Chen, H.H. 2007. Emotion Classification Using Web Blog Corpora. Web Intelligence Conference, 2-5 Kasım, Washington DC, 275-278.

[14] Tocoglu, M.A., Alpkocak, A. 2018. TREMO: A Dataset for Emotion Analysis in Turkish. Journal of InformationScience. DOI: https://doi.org/10.1177/0165551518761014.

[15] Manning, C.D., Raghavan, P., Schütze, H. 2008. Boolean Retrieval. Introduction to Information Retrieval, 1-18.

[16] Can, F., Kocberber, S., Balcik, E., Kaynak, C., Ocalan, H. C., Vursavas, O. M. 2008. Information Retrieval on Turkish Texts. Journal of the American Society for Information Science and Technology, Cilt. 59, s. 407421. DOI: https://doi.org/10.1002/asi.20750 